\title{
DESCARTES, LAS MATEMÁTICAS \\ Y LA ELABORACIÓN DE LO MODERNO
}

G.A.J. ROGERS

DEPARTAMENTO DE FILOSOFÍA

UNIVERSIDAD DE KEELE

\section{Introducción}

En el presente escrito me concentraré en precisar el lugar que tienen las matemáticas en la filosofía de Descartes y, en especial, el lugar que ocupa la geometría. Al mismo tiempo deseo revisar dos cuestiones relacionadas, que espero esclarecer cuando me ocupe del tema de las matemáticas: qué hay exactamente en la filosofía cartesiana que la distingue como "moderna" y, en segundo lugar, hasta qué punto se acercó realmente Descartes a ser moderno.

\section{El lugar de la geometría en el pensamiento del siglo xvi}

En 1623, Galileo había expresado la visión platónica en la búsqueda del conocimiento de la naturaleza:

La filosofía está escrita en este gran libro, el universo, que se encuentra continuamente abierto ante nuestra mirada. Pero el libro no puede entenderse a menos que uno primero aprenda a comprender el lenguaje y lea las letras en las que está compuesto. Está escrito en el lenguaje de la matemática y sus caracteres son triángulos, círculos y otras figuras geométricas, sin las cuales es humanamente imposible entender una sola palabra de él. ${ }^{1}$

La interpretación galileana del lugar que ocupa la geometría en las ciencias naturales contrastaba notablemente con la tradición escolástica, aún dominante en las universidades. Sin embargo, la propuesta de Galileo no se ofrecía como innovadora, sino, más bien, como una vuelta a una tradición anterior, representada por el mismo Platón, por Pitágoras antes que él y, quizás, sobre todo, por la filosofía natural de Arquímedes.

1 The Assayer, citado en Stillman Drake (comp.), Discoveries and Opinions of Galileo, Doubleday, Nueva York, 1957, pp. 227-238. 
Galileo no trató las matemáticas como una mera ayuda para llegar a la verdad en las ciencias naturales; éstas también le proporcionaban un paradigma epistémico. Al considerar la naturaleza y los límites del conocimiento humano, sostuvo (en 1632) que si bien es cierto que la extensión del conocimiento humano es muy limitada, en ciertos aspectos es comparable al de Dios:

Digo que el intelecto humano sí comprende perfectamente algunas [proposiciones], entre ellas se encuentran sólo las ciencias matemáticas, esto es, la geometría y la aritmética, en las que el intelecto divino, ciertamente, conoce infinitamente más proposiciones, pues las conoce todas. Pero, con respecto a las pocas que sí conoce el intelecto humano, creo que en certeza objetiva su conocimiento iguala al divino, pues logra entender la necesidad más allá de la cual no puede haber mayor seguridad. ${ }^{2}$

Además, Galileo explica que la naturaleza de esta comprensión, en el caso de las pruebas matemáticas, es diferente en Dios y en los seres humanos, en la medida en que Dios conoce estas verdades de una manera que es diferente de la nuestra, pues "nuestro método procede mediante un razonamiento por pasos, de una conclusión a la otra, en tanto que el suyo es una simple intuición". Dios conoce inmediatamente todas las verdades matemáticas, mientras que nosotros tenemos que trabajar mucho para obtener el conocimiento. La razón por la que nuestras mentes tienen esta capacidad (aunque sea limitada), es que "la mente humana es obra de Dios y una de las de mayor excelencia". Entonces, Galileo aceptó el paradigma matemático del conocimiento y usa el lenguaje de la intuición y de la demostración para caracterizar las diferentes formas en las que aquél puede alcanzarse. Además, será la aplicación de tal conocimiento matemático a los fenómenos de la naturaleza lo que nos permitirá entenderlos. Así, en su explicación de la resistencia de los materiales dice que mientras consideremos que las propiedades de los objetos son inmutables, "puede demostrarse geométricamente que los más grandes son siempre proporcionalmente menos resistentes que los más pequeños". 3

Cuando Galileo invocó este cuadro de la naturaleza de las relaciones entre matemáticas y conocimiento, éste ya había sido aceptado por otros. Podría sostenerse que se encuentra en Copérnico y en otros astrónomos del Renacimiento. También aparece bien ejemplificado en el prefacio de John Dee a la.primera edición en inglés de Euclides, que se publicó en 1570. Es

${ }^{2}$ Dialogue Concerning the Two World Systems - Ptolemaic and Copernican, University of California Press, Los Ángeles y Berkeley, 1962, p. 103.

3 Two New Sciences (1638); edición y traducción de Stillman Drake, University of Wisconsin Press, Madison, 1974, p. 13. 
una obra que coincide plenamente con las concepciones platónicas. "Las cosas matemáticas" (Thynges Mathematicall), dice Dee, ocupan un reino entre las cosas supranaturales - que son inmateriales y eternas-y las cosas naturales que son materiales y transitorias. Como Platón nos lo enseñó, por medio de la matemática nos podemos mover de lo transitorio a lo eterno, y las verdades matemáticas tienen las propiedades de ser "ciertas, necesarias e invencibles: concluyen de manera universal y necesaria". ${ }^{4} \mathrm{El}$ propio Dee sólo seguía una tradición que, si bien nunca se perdió por completo, tuvo un crecimiento continuo a partir de que Ficino tradujo los Diálogos de Platón, en 1484. Aunque no en todos los casos los pensadores en quienes más influyeron las ideas de Platón fueron matemáticos interesados por las ciencias matemáticas, fue entre estos últimos donde la filosofía de Platón recibió mejor acogida. El mismo Dee es un ejemplo de ello; Kepler es otro y Galileo es, claro está, un tercero, entre un cúmulo de figuras menores. ${ }^{5}$ Con todo resulta difícil saber exactamente cuánta matemática se enseñaba en las universidades. El hecho de que Hobbes, quien pasó cinco años en Oxford, parezca no haber estado familiarizado con Euclides, hasta que lo descubrió, con más de cuarenta años, en "la biblioteca de un caballero", nos hace esperar muy poco de la atención que se les prestaba a las matemáticas en Magdalen Hall.

Todo lo que he dicho hasta ahora es bastante conocido; pero quise comenzar con esta instantánea a fin de preparar la escena para la llegada de Descartes, a quien ahora nos dedicaremos.

\section{Descartes y la modernidad de la filosofía moderna}

Según John Cottingham, fueron cuatro las áreas principales en las que Descartes vio que su filosofía sustituía a la vieja y proporcionaba un sistema filosófico genuinamente nuevo:

1. Descartes intentó ofrecer una interpretación científica unificada del universo, en contraste con el enfoque fragmentario de los escolásticos.

2. Esta ciencia habría de basarse en principios matemáticos, a diferencia del aparato explicativo cualitativo de sus predecesores.

3. Descartes pretendía desarrollar un modelo mecanicista de explicación que evitara en lo posible cualquier referencia a causas y propósitos

4 The Elements of Geometrie of the Most Ancient Philosopher Euclide of Megara [...] With a very fruitfull Preface made by M.I. Dee, Londres, 1570. Las páginas del prefacio no están numeradas, pero el pasaje citado aparece en la p. 2. El prefacio tiene 50 páginas en folio.

5 John Rainolds y Thomas Jackson son dos ejemplos ingleses. Acerca de ellos, véase Mordechai Feingold: The Mathematicians Apprenticeship. Science, Universities and Society in England 1560-1640, Cambridge University Press, Cambridge, 1984, pp. 58-59. 
finales y, con esto, conferirle autonomía a la explicación científica y liberar la de su subordinación a la teología.

4. La nueva explicación comprensiva habría de abarcar por primera vez el reino de la existencia humana, incluyendo la fisiología, la medicina y una gran parte de la psicología. ${ }^{6}$

Concuerdo con Cottingham en que todas éstas son formas en las que Descartes fue un innovador y proporcionan una justificación sustancial para considerarlo el padre de la filosofía moderna. No se puede dudar de la interpretación científica unificada del mundo a la que Descartes aspiraba, pues ofreció la explicación del mundo más comprensiva y de mayor alcance que se hubiese dado desde Aristóteles. Tampoco podemos dudar de que su visión estuvo profundamente impregnada de una concepción matemáticamente inspirada de la realidad física, aunque, como lo hemos visto, en esto no es precisamente el único. Una de sus concepciones más influyentes fue, claramente, su programa positivo para ofrecer un modelo mecanicista de explicación que evadiese las categorías teleológicas. Y, finalmente, no hay duda de que la explicación comprensiva de Descartes penetró profundamente en las ciencias biológicas.

En su mayor parte, tomaré estas direcciones modernas de la filosofía cartesiana como algo dado. Deseo partir de esto, hasta cierto punto, para ampliar la lista de Cottingham pero, de manera central, para examinar atentamente el lugar que ocupan las matemáticas, especialmente la geometría, en el programa cartesiano y considerar el papel que desempeñan en su filosofía, así como su contribución a la perspectiva filosófica moderna.

Sin embargo antes de hacer esto, vale la pena mencionar al menos entre paréntesis que, aunque con énfasis diferentes, Descartes compartió la mayoría de estas aspiraciones con Hobbes, en menor medida con Galileo, y, tal vez un poco menos, con Gassendi. Así que ellos también merecen algún crédito (si es ésta la palabra correcta). en la paternidad del mundo moderno (los padres intelectuales, a diferencia de los biológicos, no tienen por qué ser únicos).

Ahora deseo considerar algunas adiciones a la lista de Cottingham. La primera de.ellas tiene que ver con la certeza y la filosofía. Como bien se sabe, Descartes se impuso como meta alcanzar un conocimiento absolutamente cierto. Hasta dónde y en qué sentido, si lo tiene, es esto parte de su

6 Cfr. John Cottingham: "Cartesian Metaphysics, Modern Philosophy", en Tom Sorell (comp.), The Rise of Modern Philosophy, The Clarendon Press, Oxford, 1993, p. 148. Las palabras son o citas directas o paráfrasis. Véase también, del mismo autor, "Cartesian Dualism: Theology, Metaphysics and Science", en John Cottingham (comp.), The Cambridge Companion to Descartes, Cambridge University Press, Cambridge, 1992, pp. 236-257. 
modernidad, es una pregunta que intentaré responder. No carece de relación con otra interrogante que surge en los estudios cartesianos modernos respecto de la posición de Descartes ante el escepticismo. Popkin sostiene que Descartes reaccionó con fuerza contra la posición escéptica de algunos de sus contemporáneos, y señala que un objetivo central, quizás el objetivo central de Descartes, era derrotar el escepticismo. ${ }^{7}$

Otra dimensión discutible de la modernidad de Descartes es su insularidad intelectual. Él se describe como el individuo autónomo, aislado, que busca la luz basándose exclusivamente en su propio esfuerzo. Para que ésta sea una visión totalmente correcta de su filosofía es necesario hacer algunas precisiones desde dos perspectivas bastante diferentes a las que me referiré en breve.

Otra cuestión sobre la que aporto algo es de índole comparativa. ¿Cómo es la contribución de Descartes a la creación del mundo moderno, en comparación con la de algunos de sus contemporáneos, incluyendo a Hobbes, y hasta qué punto difiere de ellos en algunos asuntos cruciales? Aunque éste es un tema demasiado amplio para este escrito, espero dar algunas pistas sobre el mismo.

\section{Geometría y metafísica}

Ahora consideraré el lugar que tiene la geometría en la filosofía de Descartes y, en particular, compararé el método que invoca para ésta con el que asigna a la metafísica. Mi respuesta se vinculará a la pregunta de hasta dónde hemos de considerar "moderna" la filosofía cartesiana. Defenderé dos propuestas centrales: (1) que la geometría proporciona a Descartes un modelo de conocimiento ideal que es suficientemente distintivo para permitirle romper con la filosofía tradicional, de la que estaba intentando escapar y que estaba determinado a reemplazar. Sin embargo, (2) advirtió que el modelo geométrico tenía fuertes limitaciones en su aplicación, de tal manera que sólo podría ofrecer una visión parcial de la verdadera filosofía y de su método.

Ya sabemos que Descartes no pudo dejar completamente de lado su herencia filosófica. Los estudios cartesianos de este siglo han revelado mucho acerca de las deudas que en este sentido tenía, especialmente con la tradición escolástica en la que fue educado. Pero no me referiré a estos aspectos, de lo que Descartes debe a los conocimientos antiguos; más bien quiero subrayar cómo se libra del pasado, pues quizás ningún otro pensador importante lo haya logrado tan plenamente como él. Sin embargo, de manera

7 Cfr. Richard H. Popkin, The History of Scepticism from Erasmus to Spinoza, University of California Press, Los Ángeles y Berkeley, 1979, pp. 174-192. Véase, también, del mismo autor, "Scepticism and Modernity", en The Rise of Modern Philosophy, pp. 15-32. 
algo paradójica, lo hizo con la ayuda de una de las mayores donaciones del mundo clásico a la posteridad: la geometría euclidiana. Argüiré que Descartes encontró en ella un paradigma de conocimiento que, en gran medida, difería de los que habían dominado la filosofía hasta ese momento. ${ }^{8}$ En este sentido, Descartes se inspiró en los conocimientos antiguos hasta tal punto que cuando se afirma que rompió completamente con el pasado se está tergiversando su posición, pues en la medida en que invoca ese paradigma, está apelando a una filosofía antigua. Claro está que, de alguna manera, al emplearlo repudiaba directamente la tradición escolástica en la que había sido educado. Con todo, esto por sí mismo no constituía un nuevo tipo de conocimiento. Como lo hemos visto, ya era parte de la nueva filosofía natural que Descartes conocía bien. Sin embargo, Descartes no adoptó sin reservas el paradigma euclidiano y esos matices son, a la vez, centrales para su filosofía y ejemplo de su originalidad como filósofo.

Hay una gran cantidad de formas en las que, con toda razón, se considera a Descartes original. Una, que es obvia e importante, tiene que ver con el criterio de verdad que invoca: la doctrina de las ideas claras y distintas, intimamente relacionada con la idea de certeza, a la que hemos de volver más adelante. Otra atañe a la forma como una conclusión se relaciona con sus premisas, lo cual se vincula con su rechazo del silogismo - algo a lo que también volveremos luego. Un tercer aspecto se refleja en el estilo mismo de filosofar de Descartes o, para ser más precisos, la manera como Descartes nos presenta su filosofía. Esta diferencia con sus predecesores puede expresarse de un modo muy sucinto como sigue: los dos paradigmas clásicos más importantes de la filosofía los aportaron Platón y Aristóteles. La concepción platónica fue, desde luego, el diálogo. La elucidación filosófica era producto de una dialéctica, una dinámica que requería la interacción de dos o más participantes; la esencia de este intercambio era la palabra hablada, no la escrita. La filosofía aristotélica clásica, tal como había llegado del mundo antiguo, no se presentaba, por supuesto, como un diálogo; sin embargo, la forma como se ha llegado a enseñar, a través de Santo Tomás y de comentaristas medievales posteriores, no solía diferir mucho del diálogo. Pero lo más importante es que mientras que el diálogo platónico invitaba a un intercambio intelectual como ruta hacia el conocimiento, el estudio de Aristóteles subrayaba la autoridad independiente dada al texto, moderado

8 Sin embargo, quizás se exageren esas diferencias con demasiada facilidad, debido en parte a que las categorías y cuestiones que le han preocupado a la filosofía en el siglo xx forman, en varios sentidos, una lista más corta que las que interesaron a nuestros predecesores en el siglo xvil. 
por los comentaristas autorizados por la Iglesia. En ambos casos, el estudio del texto - fuese éste diálogo o exposición y bajo la supervisión de un maestro- conducía a la comprensión.

De esta y de otras formas Descartes iba a cuestionar y a cambiar la explicación aceptada sobre la elucidación filosófica, pues la filosofía cartesiana no nació ni del intercambio de ideas con otro filósofo, a la manera de Platón, ni de las palabras de un texto clásico de Aristóteles, a la manera de Santo Tomás. Según Descartes, la comprensión filosófica era producto de la actividad del intelecto aislado y el modelo que empleó para esta nueva visión de la ruta hacia el conocimiento fue la geometría euclidiana.

Estas últimas observaciones requieren dos precisiones que, en el contexto de mi argumento, son importantes. La primera es que, aun cuando el individuo de Descartes estuviera realmente aislado de todos los demás seres humanos, nunca estaba auténticamente aislado de la Deidad, pues Dios desempeña un papel central en el sistema de Descartes, de tal modo que esto por sí mismo parecería comprometer la afirmación de Cottingham sobre la autonomía de la ciencia y de la filosofía respecto de la teología. También más adelante nos ocuparemos de señalar cuáles son exactamente las implicaciones del teísmo de Descartes para su filosofía.

La segunda precisión se refiere a la interpretación cartesiana del análisis y de la síntesis y de sus relaciones con el descubrimiento y la prueba. El paradigma euclidiano, tal como se ofrece en los libros de texto de geometría, es un ejemplo del método sintético, mientras que las Meditaciones (quizás sobre todo éstas) son un ejemplo de análisis. A Descartes no sólo le interesa proporcionar un método que justifique nuestras pretensiones de conocimiento post hoc, por así decirlo, sino también un método de descubrimiento. Lo que busca Descartes es conocimiento nuevo, no sólo conocimiento cierto, y esto es algo que se subraya en el título completo del Discours de la Méthode. Pour bien conduire sa raison, et chercher la verité dans les sciences [Discurso del método. Para bien conducir la razón y buscar la verdad en las ciencias]. La noción de buscar la verdad es justamente un rasgo distintivo de lo moderno, y hace eco a un programa que, 32 años antes, había sido identificado en el título de una de las obras más famosas de Francis Bacon, El avance del saber. La imagen del navío de la ciencia cruzando las columnas de Hércules hacia aguas desconocidas, con su idea asociada del progreso, fue central para todo el movimiento moderno. Pero Descartes sostuvo que, excepto como ayuda pedagógica, el método sintético no ofrecía nuevo conocimiento. El método analítico era el único que generaba el descubrimiento. Evidentemente, esto tuvo implicaciones importantes para el paradigma euclidiano y también es algo a lo que he de volver posteriormente. 
Escribiéndole a Plempius, tras la publicación del Discurso, Descartes explicó muy claramente la naturaleza del método que había seguido en esta obra: "usé sólo principios evidentes y, como un matemático, no tomé en cuenta sino tamaños, figuras y movimientos..." Parece como si Descartes ya hubiese advertido que las matemáticas aportan algún tipo de paradigma de conocimiento. Sigue hablando en términos que muestran cómo vio en su método algo muy distinto de otros pensadores de quienes deseaba distanciarse: "y así me separo de todos los subterfugios de los filósofos". ${ }^{10}$ Muy bien cabría preguntar cuál fue el método que, para Descartes, contrastaba desfavorablemente con el suyo y del cual quería distanciarse. Algunas de sus observaciones sobre Platón y Aristóteles, muestran parte del cuadro. Descartes considera que ambos fallan por la misma razón. De los filósofos antiguos escribió lo siguiente en el prefacio de la edición francesa de los Principos de la filosofía:

Los primeros y principales cuyos escritos tenemos son Platón y Aristóteles, entre los cuales no ha habido otra diferencia sino que el primero, siguiendo las huellas de su maestro Sócrates, confesó ingenuamente que todavía no había podido encontrar nada cierto y se contentó con escribir cosas que le parecieron verosímiles, imaginando para esto algunos principios, por los cuales trataba de dar razón de las demás cosas, mientras que Aristóteles tuvo menos franqueza, y aunque fue veinte años su discípulo, no tuvo otros principios que los suyos, cambió enteramente la manera de exponerlos y los propuso como verdaderos y seguros, aunque nada nos haga suponer que jamás los haya estimado como tales. ${ }^{11}$

Entonces, según Descartes, tanto Platón como Aristóteles fracasaron en la prueba crucial de aportar conocimiento cierto. Para él, Platón ni siquiera aspiró alguna vez a él. Aristóteles, por el contrario, falsamente sostuvo haberlo alcanzado pero, de hecho, nunca lo hizo.

Otra objeción a los filósofos en general, tanto anteriores como contemporáneos, fue que eligieron presentar sus argumentos en forma silogística. El razonamiento silogístico, como tal, no estaba demasiado equivocado, pues su aplicación correcta podría llevar de premisas verdaderas a conclusiones

9 Esto aparece en una carta en la que comenta las críticas al Discurso hechas por Libert Froidmont; veáse OEuvres de Descartes, edición de Charles Adam y Paul Tannery, 2a. ed., 11 vols., Vrin, París, 1974-1986, en adelante citado como AVT, vol. i, pp. 410-411. [La paginación citada corresponde a las CEuvres de Descartes de 1996. $\mathrm{N}$ del t.]

10 AVT i, 410-411.

11 AVT ix b, 5-6. 
verdaderas; sin embargo, adolecía de dos debilidades fatales: en primer lugar, no ampliaba el conocimiento, pues no aportaba un método de descubrimiento; en segundo, el silogismo no proporcionaba ningún método para identificar la verdad en sus premisas. El problema con la lógica, según Descartes, es que los "silogismos y la mayoría de sus demás instrucciones, sirven más bien para explicar a otro las cosas que se sabe [...] más que aprender [nuevas]". 12 "Y aunque en efecto contiene muchos preceptos muy verdaderos y muy buenos hay, sin embargo, tantos otros mezclados con ellos que son dañinos. .."13 que, de hecho, impide el avance del conocimiento.

Sería erróneo extraer de tales observaciones la conclusión de que Descartes se oponía totalmente a enseñar lógica tradicional como un ejercicio pedagógico. Una clara prueba de esto es que en 1638, un año después de la publicación del Discurso, recomendó el colegio de La Flèche para la educación del hijo de un amigo. ${ }^{14} \mathrm{Y}$ esta recomendación es congruente con algunas observaciones que aparecen en el Discurso, las cuales en ocasiones se pasan por alto o se consideran sólo por su carácter irónico. Después de un ataque contra la educación que recibió en La Flèche, que no le había dejado más que un "creciente reconocimiento de su ignorancia", 15 en fuerte contraste, el siguiente párrafo enumera los méritos de estudiar las obras que le exigieron sus profesores jesuitas. Incluso las que estaban llenas de superstición y falsedad habían sido útiles y una de sus ventajas-que no la menor- es que le habían permitido conocer su verdadero valor e "impedir que las mismas lo engañaran". ${ }^{16} \mathrm{El}$ problema real con la filosofía que le habían enseñado, sin embargo, no era su falsedad, sino su carencia de certeza. Incluso tras siglos de haber sido cultivada por los mejores espíritus, "no hay todavía en ella nada que no sea tema de disputa y, por consiguiente, que no sea dudoso". ${ }^{17}$

Descartes dice que tampoco en la teología puede encontrar un camino simple hacia la verdad y la certeza. Si bien en este caso sus observaciones parecen ser una confesión de ignorancia, quizás también representen, de manera más profunda, un repudio velado a la Iglesia. Descartes señala que se dio cuenta de que para alcanzar la verdad teológica por su propio esfuerzo, "necesitaba alguna extraordinaria asistencia del cielo y ser más que

12 Discurso del método (en adelante, DM), A/T vi, 17.

13 Ibid.

14 Cfr. A/T ii, 378.

$15 \mathrm{DM}, \mathrm{A} / \mathrm{T}$ vi, 4.

16 Ibid., 6.

$17 \mathrm{DM}, \mathrm{A} / \mathrm{T}$ vi, 8. 
hombre". ${ }^{18}$ Es ésta una opinión que difícilmente encaja con lo que expresa en La recherche de la verité par la lumiere naturelle: "Esta luz, por sí sola, sin ayuda alguna de la religión o de la filosofía, determina qué opiniones, acerca de cualquier asunto que le pueda pasar por la cabeza debe mantener un hombre bueno, y penetra los secretos de las ciencias más recónditas."19 Ésta es una observación que, finalmente, deja poco espacio al papel tradicional de la Iglesia como mediadora, y quizás. no sea de sorprender que no haya sido publicada en vida de Descartes.

Así pues, parece más probable que la posición oficial y públicamente enunciada de Descartes con respecto a los asuntos teológicos, refleje con más plenitud su deseo de tener una vida tranquila, en lugar de una vida que fluya de la convicción interior. En el "Sequitur examen programmatis", de su "Notæ in programma"..., escrito diez años después en el contexto de la disputa con Regius, Descartes distingue tres tipos diferentes de cuestiones, (a) algunas que se creen sólo por la fe - los misterios de la encarnación y el de la Trinidad, por ejemplo; (b) otras que puede investigar la razón natural, como la existencia de Dios y la diferencia entre el alma humana y el cuerpo; y (c) cuestiones como el problema de cuadrar el círculo o de hacer oro mediante la alquimia. Así como es un abuso de las Sagradas Escrituras esperar resolver problemas del tercer tipo apelando a la Biblia, "también pierden su autoridad quienes admiten que las primeras cuestiones deben ser demostradas con argumentos tomados únicamente de la filosofía". ${ }^{20}$ Sin embargo, los filósofos tienen la aprobación de los teólogos para buscar respuestas a cuestiones del segundo tipo mediante la razón humana. Como Descartes lo formula en la carta de dedicatoria a la Sorbona, al comienzo de las Meditaciones, que igualmente con seguridad debe concederse que es tanto una defensa de su propio trabajo, como una declaración con un objetivo pacifista, "Siempre he considerado que estas dos cuestiones de Dios y del alma eran las que principalmente deben ser demostradas por las razones de la filosofía antes que por las de la teología". ${ }^{21}$ Descartes estaba consciente de que era poco probable que su posición, en este caso fuera polémica desde un punto de vista teológico; para él era realmente muy importante que no lo fuera. Pero dista mucho de ser claro que su posición epistemológica, encaminada como lo está a la búsqueda del conocimiento cierto y universal, sea compatible con todos sus pronunciamientos públicos sobre asuntos religiosos.

18 Ibid.

19 A/T x, 495.

20 A/T viii $b, 353$.

21 A/T vii, 1. 


\section{¿El paradigma geométrico?}

Precisamente antes de sus observaciones sobre teología en el Discurso, Dèscartes habla del deleite temprano que tuvo con las matemáticas. Esto se derivó, inicialmente, de la certeza y de la evidencia de los razonamientos matemáticos; aunque, según él, entonces todavía no apreciaba su importancia real y pensaba que sólo eran útiles en las artes mecánicas. Gradualmente, sin embargo, habrían de convertirse en mucho más, pues, en la naturaleza particular de la inferencia geométrica - y es la geometría más claramente, que otras ramas de la matemática, la que proporciona el paradigma-, Descartes llegó a discernir el universal de la investigación racional humana. Aun cuando el programa de las primeras Regulæ habría de modificarse sustancialmente antes de que emergiese la filosofía madura de Descartes, gran parte de su pensamiento permaneció intacto en lo que se refiere a la naturaleza del conocimiento y al paradigma que las matemáticas ofrecían. "Toda la ciencia es un conocimiento cierto y evidente", dice en la "Regla II"; y, siguiendo a Galileo, sostuvo que de todas las ciencias sólo la aritmética y la geometría están "exentas de todo vicio de falsedad o incertidumbre". ${ }^{22}$ Descartes ya había enunciado que su primera tarea sería alcanzar juicios verdaderos y correctos, y la expresó en la "Regla II" de la siguiente manera: "Debemos ocuparnos únicamente de aquellos objetos que nuestro espíritu parece poder conocer de un modo cierto e indudable." ${ }^{23}$ Se propone contrastar esta meta con la de los escolásticos que se dedican a discutir "silogismos probables". Atribuye el éxito de las matemáticas para lograr certeza, al hecho de que "sólo ellas poseen un objeto tan puro y simple que no es necesario hacer ninguna suposición que la experiencia haya hecho incierta". ${ }^{24} \mathrm{Y}$, en lugar de extraer la conclusión negativa de que sólo la matemática puede ser scientia (algo que parecería implicar la palabra "sólo"), la tarea era identificar otros objetos que "ofrezcan una certeza igual a las demostraciones aritméticas y geométricas". ${ }^{25}$ Es ésta precisamente la forma que tiene Descartes de capturar el universal del conocimiento en el caso particular de la matemática.

Así, parecería que Descartes usa la matemática para ofrecer un paradigma de conocimiento y que el paradigma así obtenido se caracteriza por su autonomía. Lo que quiero decir con esto es que la intuición se garantiza

22 Reglas para la dirección del espíritu, AVT x, 364. Probablemente, las Regulæ fueron escritas en varias etapas: las primeras, en su mayor parte, escritas entre 1619-1620, y las posteriores entre 1626-1628. Para la datación, véase Stephen Gaukroger, Descartes: An Intellectual Biography, Clarendon Press, Oxford, 1995, esp. las pp. 111-112, y las referencias que ahí se dan.

23 A/T x, 362.
24 A/T x, 365.
25 A/T x, 366. 
a sí misma o que es necesario que lo haga. Descartes dice en la "Regla V" que todo el método consiste en "reducir gradualmente las proposiciones complicadas y oscuras a otras proposiciones más simples y, partiendo de la intuición de las más simples, tratamos de elevarnos por los mismos grados al conocimiento de todas las demás". ${ }^{26} \mathrm{Y}$, con respecto a lo simple y lo complejo, en la "Regla VI" distingue entre lo absoluto y lo relativo en términos de su utilidad para su proyecto. "Llamo absoluto a todo lo que contiene en sí la naturaleza pura y simple a que se refiere una cuestión: por ejemplo todo lo que se considera independiente, causa, simple, universal, uno, igual, semejante, recto u otras cosas de esta índole; y al mismo tiempo lo llamo lo más simple y lo más fácil para utilizarlo en la solución de las cuestiones." $27 \mathrm{~A}$ partir de este pasaje es difícil decir con exactitud qué es lo que Descartes entendía por una naturaleza simple. Se obtiene más claridad sobre este asunto en "Sequitur examen programmatis" de sus Notæ in programma... - texto más tardio-, aun cuando aquí se refiera no a "naturalezas", sino a entes simples y compuestos. Descartes escribe: "es compuesto aquello en que se encuentran dos o más atributos, de los cuales cada uno puede ser entendido distintamente sin el otro [...]; en cambio ente simple es aquel en el que no se encuentran tales atributos". ${ }^{28}$ Los ejemplos que da Descartes de entes simples en este contexto son del cuerpo y la mente, cada uno de los cuales, según sostiene, puede entenderse sin invocar al otro.

Veremos, o al menos lo argüiré, que el compromiso aparente de Descartes con la autonomía de nuestro conocimiento de las naturalezas simples no es algo que desee mantener en un sentido absoluto; tiene que precisarse en un aspecto muy importante. Pero por el momento continuemos con el lugar que ocupa el análisis en su sistema, lo que nos llevará a su explicación de las ideas claras y distintas.

\section{Análisis y síntesis}

Descartes aclara, en muchos lugares, que el conocimiento comienza de lo particular y no de lo universal. Como le escribió a Clerselier, en respuesta a una objeción de Gassendi:

el error más importante que comete nuestro crítico [...] es suponer que el conocimiento de las proposiciones particulares debe siempre deducirse de las universales, siguiendo el mismo orden que el de un silogismo en la Dialéctica [lógica escolástica]. En esto muestra lo poco que sabe de la manera como hemos

\footnotetext{
26 A T x 379.

27 A T x , 381-382.

28 AVT viii, 350-351.
} 
de buscar la verdad. Es cierto que si hemos de descubrir la verdad, siempre debemos comenzar con las nociones particulares a fin de, posteriormente, llegar a las generales... ${ }^{29}$

Éste es, en esencia el método de análisis. Descartes ha explicado lo que quiere decir con análisis y síntesis en la réplica al segundo conjunto de Objeciones. Ambos son métodos de demostración y deben en sí mismos distinguir entre el orden y el método. El análisis, dice, es el método que se sigue en las Meditaciones, mientras que la síntesis caracteriza el método geométrico. Descartes explica el análisis de la siguente manera:

El análisis muestra la forma verdadera por medio de la cual la cosa en cuestión se descubrió metódicamente y a priori, por así decirlo, de tal manera que si el lector está dispuesto a seguirlo y presta suficiente atención a todos los aspectos, se apropiará de la cosa y la comprenderá tan perfectamente como si la hubiese descubierto por sí mismo. ${ }^{30}$

Es probable que por a priori Descartes quiera decir en este contexto que debemos ver, de manera inmediata, que la proposición en cuestión debe de hecho ser verdadera. Así que el entendimiento y la verdad se dan conjuntamente.

La síntesis la explica así:

La síntesis, en contraste, emplea un método directamente opuesto, y la búsqueda, por así decirlo, es a posteriori [... E] Ésta, demuestra claramente la conclusión y emplea una larga serie de definiciones, postulados, axiomas, teoremas y problemas, de tal manera que si alguien niega una de las conclusiones puede mostrarse, de inmediato, que ésta está contenida en lo anterior. ${ }^{31}$

Su mayor desventaja es que no revela cómo se descubren las cosas. Éste fue el método usado explícitamente por los geómetras antiguos, aunque Descartes cree que también usaron un método secreto de análisis para llevar a cabo sus descubrimientos.

Teniendo en cuenta que los axiomas de la geometría son evidentemente claros, el método de la síntesis es el apropiado para esa disciplina. Sin embargo, la posición es muy distinta con respecto a la metafísica. Aqui "no hay nada que exija tanto esfuerzo como el hacer clara y distinta nuestra percepción de las nociones primarias". ${ }^{32}$ Luego subraya lo siguiente: tene-

29 A $\mathrm{T}$ ix, 205-206.

30 A T vii, 155. [Para Descartes, a priori se encuentra, naturalmente, más cerca de la versión escolástica que de la kantiana posterior, por lo cual el término se restringe al conocimiento analítico (análisis conceptual). $\mathrm{N}$. del t .]

31 AVT vii, 156.

32 A T vii, 157. 
mos que superar nuestros prejuicios en asuntos que desde la más temprana infancia; hemos aceptado; sólo quienes "realmente se concentren, mediten y extraigan su mente de las cosas corporales hasta donde esto sea posible, alcanzarán un conocimiento perfecto de ellas". ${ }^{33}$ Justo por esto, afirma, denominó su obra "Meditaciones" y no, como los filósofos, "Disputaciones" o como los geómetras, "teoremas y problemas". A diferencia de las verdades matemáticas, las de la metafísica están lejos de ser evidentes.

Así, para Descartes, la metafísica difiere de manera importante de la geometría. Mientras que la síntesis proporciona un método de presentación para la geometría y ésta puede enseñarse exitosamente empleando la presentación sintética, algo muy diferente sucede con la metafísica; tampoco podríamos continuar apegándonos al método de pensadores anteriores. Alcanzar la verdad en filosofía - ¿y cuál si no es su objetivo?- depende de alcanzar una convicción personal sobre cuestiones fundamentales. Esa convicción personal requiere alcanzar una certeza intelectual incorruptible acerca de conceptos que son, de suyo, extremadamente difíciles de captar. Alcanzar ideas claras y distintas acerca de Dios, del yo, de la mente y el cuerpo (para tomar algunos de los ejemplos más obvios) plantea una dificultad intelectual de un orden muy diferente del que interviene al advertir, digamos, que "la distancia más corta entre dos puntos es una línea recta".

Sin embargo, una vez alcanzada la claridad sobre los conceptos metafísicos básicos, al filósofo le será posible presentar sus descubrimientos de manera geométrica, y de hecho esto es justo lo que Descartes hace en el documento que he estado citando, "Las réplicas del autor al segundo conjunto de Objeciones". Bajo el encabezado "Argumentos que prueban la existencia de Dios y la distinción entre el alma y el cuerpo, presentados de manera geométrica", Descartes procede a presentar definiciones, postuiados, axiomas y proposiciones. Y los Principios de la filosofía, publicado dos años después, es precisamente una obra comprensiva de este tipo. ${ }^{34}$

Por lo tanto, el lugar central que el análisis ocupa en el programa cartesiano, surge de la presentación estándar de la geometría clásica, y con frecuencia se ha señalado que la propia obra geométrica de Descartes no sigue el método sintético al que él se oponía; aunque tampoco queda claro si puede clasificarse como seguidor estricto del método analítico avalado. La obra en la que se sigue el método analítico de la manera más patente, es

33 Ibid.

34 Al menos debemos tomarla así si aceptamos el registro de Burman en el que se traza el contraste entre los métodos de las Meditaciones y de los Principios: "En los Principios, su propósito es la exposición y su procedimiento es sintético" (Descartes' Conversation with Burman, trad. introducción y comentario de John Cottingham, Clarendon Press, Oxford, 1976, p. 12). 
las Meditaciones; sin embargo, excepto como un ejemplo ocasional, en ella apenas figura la geometría.

\section{Dios en el sistema cartesino}

Aun cuando la primera verdad cierta que Descartes descubrió en su reconstrucción es la de su propia existencia, es bien sabido que en muchos pasajes subraya que la verdad que funda su sistema es la de la existencia de Dios. Al final de la "Quinta meditación", Descartes escribe: "Y así reconozco muy claramente que la certeza y la verdad de toda ciencia depende únicamente del conocimiento del verdadero Dios, de modo que antes de conocerlo no podía saber perfectamente ninguna otra cosa." 35 Fue precisamente este conocimiento de Dios lo que permitió proseguir para construir toda una explicación, no sólo de la metafísica, sino también de la filosofía natural. Y así continúa, "Y ahora que lo conozco poseo el medio de adquirir una ciencia perfecta respecto a una infinidad de cosas, no solamente de aquellas que están en él, sino también de las que pertenecen a la naturaleza corporal, en cuanto puede servir de objeto a las demostraciones de los geómetras, que no tienen relación con su existencia". ${ }^{36}$ Ya había expresado una posición similar unos diez años antes, en una carta a Mersenne:

Pienso que todos aquellos a quienes Dios les ha dado el uso de esta razón [humana] tienen la obligación de emplearla principalmente en la tarea de conocerlo a él y de conocerse a sí mismos. Ésa es la tarea con la que comencé mis estudios y puedo decir que no habria sido capaz de descubrir los fundamentos de la física si no los hubiese buscado a lo largo del camino [...] Pienso que he sido capaz de probar verdades metafísicas de una manera que es más evidente que las demostraciones de la geometría. ${ }^{37}$

Así pues, concuerdo con los estudiosos cartesianos que desean sostener que hay un sentido en el cual la primera verdad de Descartes no es la de su propia existencia, sino la de Dios, aun cuando en el orden de análisis de las Meditaciones aparezca primero el descubrimiento de su propia existencia. Descartes explicó esto en la cuarta parte del Discurso, cuando dijo que la duda siempre sería posible "si no presuponen la existencia de Dios. [...] Esto mismo que he tomado como una regla, a saber, que las cosas que concebimos muy clara y muy distintamente son verdaderas, sólo es seguro

35 AVT ix, 56.

36 La versión francesa continúa, "sino también de las que pertenecen a la naturaleza corporal, en cuanto puede servir de objeto a las demostraciones de los geómetras, que no tienen relación con su existencia".

$37 \mathrm{~A} / \mathrm{T} \mathrm{i}, 144$. 
porque Dios es o existe, y porque es un ser perfecto y porque todo lo que está en nosotros procede de él". ${ }^{38}$ Tal como Descartes se lo explicó a Burman, cuando buscaba una elucidación casi del mismo texto: "Si no supiésemos que toda verdad tiene su origen en Dios, entonces, por más claras que fuesen nuestras ideas, no sabríamos que eran verdaderas o que no estábamos equivocados." 39 Así, según este punto de vista, parece correcto ver a Descartes como un pensador cuya filosofía no puede separarse de su compromiso central con la Deidad sin sufrir una profunda distorsión.

Esto se subraya, además, por su compromiso con la creación de las verdades eternas, el cual se sigue del principio cartesiano de que todo depende ontológicamente de la Deidad: "es manifiestamente claro que no puede haber nada que no dependa de él [. . . ], no puede haber ningún tipo de entidad que no dependa de él", incluyendo las verdades eternas que "Dios, como el legislador eterno, ha ordenado [...] desde la eternidad". ${ }^{40}$ Por lo tanto, la filosofía de Descartes sería inimaginable sin una Deidad.

$\mathrm{Y}$, sin embargo, hay un sentido importante en el que esto no es así. Como lo hemos visto, Descartes está fuertemente comprometido con lograr la certeza; pero, en última instancia, ¿hasta qué punto fue importante eso para él? Y, ¿hasta qué punto fue importante para sus seguidores y para su influencia? En cuanto a la última pregunta, la respuesta seguramente debe ser "No mucho". La filosofía de Descartes, aun para sus discípulos más devotos, muy pocas veces se ofreció como una certeza concluyente. Mucho más común fue la respuesta de su expositor Jacques Rohault, quien, en su Traité de physique de 1671, advertía que "en su mayor parte debemos contentarnos con descubrir cómo pueden ser las cosas, sin pretender llegar a un conocimiento cierto de cómo son realmente, pues es posible que haya diferentes causas capaces de producir el mismo efecto". ${ }^{41} \mathrm{Y}$ cuando vamos al propio texto de Descartes, hay signos de que él también, al menos algunas veces, adoptó la opinión hipotética acerca de sus propias explicaciones. ¿De qué otra manera, por ejemplo, hemos de dar cuenta de sus palabras en la sección final de los Principios de la filosofía? Tras hablar con algún detalle del método que ha seguido, reconoce que su explicación de la mecánica de la naturaleza podría no ser como lo supone su teoría: "Aun cuando este método pueda permitirnos entender cómo podrían haber surgido todas las cosas en la naturaleza, no ha de inferirse, por consiguiente, que de hecho se hicieron de esta manera; [...] el supremo artesano del mundo real pudo

38 AVT vi, 38.

39 Descartes' Conversation with Burman, loc. cit., pp. 49-50.

40 "Sextas respuestas", A/T vii, 435-436.

41 Citado de Rohault's System of Natural Philosophy, Illustrated with Dr. Samuel Clarke's Notes. . . trad. John Clarke, Londres, 1723, p. 14. 
haber producido todo lo que vemos de muy diferentes maneras." ${ }^{2}$ Pero, continúa, la certeza moral de sus explicaciones se mantiene porque difícilmente se podría explicar tanto si fuesen falsos los principios originales. ${ }^{43}$ Así pues, parecería que al menos en lo que toca a la filosofía natural hay evidencia textual que apoya la interpretación hipotética de Descartes y que se ha rebajado la motivación original de la meta de la certeza.

\section{Descartes y la modernidad}

Es este último tema el que ahora puede llevarnos de vuelta a la cuestión de Descartes como fundador de la modernidad. Al comienzo señalé que hay muchas formas en las que es correcto ver a Descartes como el padre de la filosofía moderna. Fue él quien rompió decisivamente con el escolasticismo y quien introdujo una concepción mecánica de la naturaleza tan íntimamente ligada a la geometría que él mismo las presentó casi como un mismo tema. Y, en cuanto a la filosofía personal, el mensaje que fluía de las Meditaciones era que el individuo solitario, sin más ayuda que sus propias facultades intelectuales, podía llegar a la verdad en cualesquiera de los temas abiertos al escrutinio humano. En ese sentido, la filosofía cartesiana coincidía totalmente con la del individualismo creciente que surgía en parte de la teología de Lutero y del capitalismo floreciente, y que encontraba una expresión independiente en las filosofías de Hobbes y de Locke. Fue en el paradigma griego del conocimiento, la geometría euclidiana, donde Descartes encontró el modelo que le permitió hacer ese rompimiento decisivo con el pasado, pues en él encontró una expresión del intelecto racional, que opera en el nivel de abstracción más alto pero, también, de una manera que realmente se ligaba al mundo, tal como lo encontramos.

Sin embargo, de manera irónica, la meta que Descartes se impuso, capturada en la carta a Mersenne de 1640, de que "pensaría que no sé nada de física si sólo pudiese decir cómo podrían ser las cosas, sin demostrar que no podrían ser de otra manera", lo que era "perfectamente posible una vez que se había reducido la física a las leyes de la matemática [y] lo que creo que puedo hacer para la pequeña área a la que se extiende mi conocimiento", ${ }^{44}$ una aspiración fundamental para todo su programa, fue casi la primera de sus contribuciones para que sus seguidores, desde luego no todos, abandonaran la visión moderna; aunque importante, Spinoza no es sino una excepción. Pero la tendencia general fue con fuerza en su contra. Hobbes es un ejemplo obvio de esa tendencia, pues aunque compartía muchas de las

42 Principios IV parte, §204; AVT ix b, 322.

43 Principios IV parte, §205; A/T ix b, 323.

44 AVT iii, 39. 
tesis cartesianas acerca de cómo había que llevar a efecto la filosofía y pedía hacer de la política (y de la física) una ciencia y, por lo tanto, cierta, siempre matizó esa certeza admitiendo que las premisas de su explicación eran hipotéticas, no categóricas. La certeza matemática era una cosa y la física o la política era otra. Sus ontologías diferentes necesitaban epistemologías diferentes, pues si bien Hobbes coincidía con Descartes en que el método de descubrimiento era analítico y precedía a la síntesis, y que lo universal debe descubrirse en lo particular, no reclamaba ninguna certeza absoluta para los descubrimientos de las ciencias naturales. Sus conclusiones eran todas hipotéticas, tal como lo expresó al estudiar las causas del movimiento: "Y suponiendo que algún movimiento es la causa de tu fenómeno, intenta ver si por una consecuencia evidente, sin contradecir ninguna otra verdad o experimento manifiesto, se puede derivar de tu suposición la causa que buscas. Si puedes, eso es todo lo que de la filosofía se espera, en cuanto a esa cuestión, pues no hay ningún efecto en la naturaleza cuyo Autor no pueda hacer que suceda de más de una manera." 45 Esto muy bien puede recordarnos las palabras antes citadas de las secciones finales de los Principios de Descartes; pero para Hobbes no había ambivalencia acerca del carácter hipotético de sus explicaciones.

Sin duda esto se explica en parte porque Hobbes no invocaba a ningún Dios garante dentro de su sistema y, en general, parece haber algún tipo de correlación directa entre la cantidad de trabajo explicativo que un filósofo asigna a Dios y el grado de certeza que atribuye a sus explicaciones (aunque ésta es una aseveración que requeriría argumentarse mejor). Pero la mayoría de los filósofos que vinieron después de Hobbes, en especial, aunque no exclusivamente, los de la tradición empírica, abandonaron en su filosofía la meta cartesiana de la certeza, aun cuando lo siguieran en muchas otras cosas. Para bien o para mal, fueron las probabilidades, más que las certezas, lo que se convirtió en la marca distintiva de lo moderno.

Septiembre de 1996 Traducción de José A. RoBles

45 Decameron Physiologicum; or Ten Dialogues of Natural Philosophy. (1678), The English Works of Thomas Hobbes, William Molesworth, Londres, 1839, vol. vii, p. 88. Ésta fue la última de todas las obras de Hobbes; se publicó cuando tenía más de noventa años, pero la misma posición se encuentra en otras muy anteriores, por ejemplo, el Leviathan. 